\title{
The Construction of Political Theory Courses and the Marx Doctrine Study on the Problem of the Popularization of China Era
}

\author{
Huang Qinggui \\ Fujian Polytechnic of Information Technology, Fuzhou, Fujian, China, 350003
}

\begin{abstract}
The construction of political theory course is suitable for the characteristics of higher vocational education, must take the Marx doctrine Chinese, popularization, modernization as the angle of view, the understanding of Marx's Chinese and popularization, the age, the scientific connotation, necessity, contents, ways and methods, to explore the new situation and how to make ideological and political theory of class as students love and benefit from the life course, is to achieve the goal of personnel training mission and requirements.
\end{abstract}

Keywords - The political theory course, Marx's Chinese, popularization, modernization, research

\section{马克思主义中国化大众化时代化与政治理论课程建设 问题研究}

\author{
黄庆贵 \\ 福建信息职业技术学院, 福州, 福建, 中国, 350003
}

\begin{abstract}
摘 要 构建适合高职教育特点的政治理论课程建设, 必须以马克思主义中国化、大众化、时代化为视角, 科学理解马克思主义 中国化、大众化、时代化的科学内涵、客观必然性、主要内容、实现途径和方法等问题, 探索新形势下如何使思想政治理论课成为学 生喜欢和终生受益的课程, 是实现高校人才培养目标的使命和要求。
\end{abstract}

关键词＼cjkstart政治理论课程，马克思主义中国化、大众化、时代化，研究

\section{1. 引言}

习近平总书记在 2013 年 8 月 19 日全国宣传思想工作 会议上的重要讲话中强调: “宣传思想工作就是要巩固马克 思主义在意识形态领域的指导地位, 巩固全党全国人民团 结奋斗的共同思想基础。”十八届三中全会通过的《中共中 央关于全面深化改革若干重大问题的决定》指出: “建设社 会主义文化强国, 增强国家文化软实力, 必须坚持社会主 义先进文化前进方向, 坚持中国特色社会主义文化发展道 路, 培育和践行社会主义核心价值观, 巩固马克思主义在 意识形态领域的指导地位, 巩固全党全国各族人民团结奋 斗的共同思想基础。”两个巩固是面对新形势下宣传思想工
作环境、对象、范围、方式的新变化以及对文化建设以及 高校思想政治教育工作提出的新要求和新任务,有助于推 动马克思主义理论的中国化大众化时代化。我们以马克思 主义中国化大众化时代化为研究视角, 科学理解马克思主 义中国化大众化时代化的客观必然性、科学内涵、主要内 容、实现途径以及方法等问题, 探索新形势下如何实现思 想政治理论课程建设过程中实现马克思主义中国化、大众 化、时代化问题的新途径和新方法, 使思想政治理论课成 为学生喜欢和终生受益的课程, 是实现高校人才培养目标 的使命和要求。马克思主义中国化大众化时代化是有机整 体, 是马克思主义和党的理论创新的永恒主题。

福建省教育厅社会科学基金项目支持（资助号: JA11427S） 


\section{2. 思想政治理论课程建设承担着宣传马克思主义中 国化中国化、大众化、时代化的使命}

2.1 “马克思主义中国化”命题的提出、涵义及其客观必然性

\subsection{1 “马克思主义中国化”的提出}

1938 年毛泽东在《论新阶段》政治报告中强调指出: “马克思主义的中国化, 使之在其每一表现中带着中国的特 性, 即是说, 按照中国的特点去应用它, 成为全党亟待了 解并亟须解决的问题。”这是党首次明确提出 “马克思主义 中国化”的重大命题, 对后来党的理论发展和事业推进具有 深远影响。毛泽东思想在七大确立为党的指导思想并载入 党章, 也是党推进马克思主义中国化过程中的第一个重大 理论成果。

\subsection{2 “马克思主义中国化”的涵义}

马克思主义中国化就是将马克思主义基本原理同中国 具体实际相结合, 就是如何用马克思主义基本原理更进一 步地同中国革命建设改革实践、中国的优秀历史传统和优 秀文化结合起来, 使马克思主义在中国实现具体化即毛泽 东思想和中国特色社会主义理论体系。

\subsection{3.马克思主义中国化的客观必然性}

\subsubsection{1 开放性是马克思主义中国化的基本要求}

马克思主义来源于德国, 所以开放性是马克思主义理 论和中国共产党人的特质。毛泽东以对民族音乐理解的视 角提倡中国民族音乐来说明马克思主义中国化, 军乐队用 唢呐、胡琴的形式而不能穿前胸后背写着“勇”字的补子来 说明民族化。为消除苏共的疑虑, “马克思主义中国化”在 20 世纪 50 年代初出版《毛泽东选集》时改为“马克思主义 在中国的具体化” 以及“毛泽东思想”的提法问题, 十一届三 中全会后“马克思主义中国化”概就广泛使用。马克思主义 中国化是指马克思主义民族化 (即马克思主义理论的包容 性）和时代化（即马克思主义理论的发展性）所具备世界 眼光。时代化和民族化统一于马克思主义中国化的实践过 程中。

\subsubsection{2 世界眼光成就中国化马克思主义理论}

毛泽东在革命和建设年代用世界眼光创立毛泽东思 想, 比较系统地观察和了解世界发展态势, 深入研究中国 革命建设和世界革命建设的关系, 科学回答什么是马克思 主义, 怎样对待马克思主义问题。 《新民主主义论》就是 坚持世界眼光来分析中国革命特点和规律的典范。坚持世 界眼光就是要借鉴和吸收进步的外国文化, 实现中国的和 外国优秀文化的有机地结合, 用中西结合的形式来促进中 国优秀文化向前发展; “洋为中用”, 学习外国的东西是“把 学的东西中国化”, “创造出中国自己的、有独特的民族风
格的东西”, “使我们自己的东西有一个跃进”, 就是批判地 吸收外国优秀文化, 以思想开放、有容乃大的世界眼光来 审视中国革命的经验, 提出完整的新民主主义革命理论, 形成马克思主义中国化理论成果毛泽东思想。

改革开放的世界眼光促进中国特色社会主义理论的创 立。十一届三中全会以来, 党的几代领导人开阔的世界眼 光, 领导人民改革开放和现代化建设, 推进马克思主义中 国化, 开创和发展包括邓小平理论、“三个代表”重要思想 和科学发展观在内的中国特色社会主义体系。十八大以来, 习近平总书记发表系列讲话, 深刻回答了新的历史条件下 党和国家发展的重大理论和现实问题, 丰富发展了中国特 色社会主义理论体系。中国特色社会主义理论体系紧密结 合我国改革开放和现代化建设的实际，紧密结合新的时代 条件, 着重思考和回答什么是社会主义、怎样建设社会主 义, 建设什么样的党、怎样建设党, 实现什么样的发展、 怎样发展以及建设什么怎样的民主, 怎样实现民主等重大 课题, 在认真总结社会主义建设历史经验和最新经验的基 础上, 创造性地提出包括社会主义本质理论、社会主义初 级阶段理论、社会主义改革开放理论、社会主义经济建设、 政治建设、文化建设、社会建设、生态文明建设等理论、 实现祖国完全统一理论、走和平发展道路的理论、马克思 主义执政党建设理论等内容, 丰富和发展马克思列宁主义、 毛泽东思想。中国特色社会主义理论体系同毛泽东思想是 一脉相承而又与时俱进的, 这个“承”和“进”, 主要就体现 在以上这些新思想、新观点、新论断上。

\subsubsection{3 正确认识和处理社会主义与资本主义的关系是世界} 眼光的核心

正确认识和处理社会主义与资本主义关系是世界发展 的大背景下坚持世界眼光的核心。在处理这个问题上存在 着“全盘西化”论和全盘否定资本主义论两种错误论调, “全 盘西化”论照搬西方政治经济模式，走资本主义道路；全盘 否定资本主义论要让资本主义在中国“绝种”。十一届三中 全会后, 以世界眼光审视和平与发展成为时代主题, 对社 会主义与资本主义关系问题才得到正确和比较正确的解 决。主要体现在三个方面:

\subsubsection{1 继承和借鉴}

社会主义与资本主义关系是既对抗和继承又对立和统 一关系, 毛泽东在论证社会主义代替资本主义是两者继承 关系，认为中国资本主义因素是少了还要有 “广大发展”; 三大改造基本完成后还提出“可以消灭了资本主义, 又搞资 本主义”的正确主张，但后来没有坚持下来。十一届三中全 会后, 邓小平从从哲学的视角审视社会主义与资本主义关 系既对立统一又可转化和互补; 从政治视角审视资本主义 
几百年的发展史, 必须继承和学习她的科学技术、有益知 识和经验。胡锦涛的科学发展观是立足于社会主义初级阶 段基本国情, 总结我国发展实践, 借鉴国外发展经验, 适 应新的发展要求提出来的。所以改革开放关于社会主义对 资本主义要继承和借鉴的认识有了巨大进步。

\subsubsection{2 共存和补充}

毛泽东阐述社会主义与资本主义共存和补充关系但未 能实施。邓小平提出“一国两制” 是对社会主义与资本主义 共存和补充关系的丰富和发展, 允许社会主义与资本主义 长期共存, 更有利于发展社会主义; 以社会主义经济为主 体的社会主义基本经济制度的经济基础很大, 吸收外资作 为我国社会主义建设不可缺少的补充, 是社会主义市场经 济的重要组成部分, 对社会主义发展有利。我们运用资本 主义某些方法, 对发展生产力有利, 中国不用资本主义某 些方法, 就无路可走。

\subsubsection{3 辨析和吸纳}

毛泽东提出对资本主义要加以辨析和吸纳的总体思想 和原则而没有具体展开。改革开放是邓小平对资本主义的 辨析和吸纳思想讲得最明确、发挥最好, 运用最为广泛, 认为资本主义创造文明成果, 反映现代社会化生产规律的 先进管理方法, 市场经济也可以为社会主义服务, 奠定社 会主义市场经济理论基础, 是马克思主义中国化发展的新 阶段的标志; 认为国际上阶级斗争是长期的存在的, 有时 甚至会激化, 必须用革命两手对付反革命两手; 国内阶级 斗争要保持清醒头脑和正确斗争方法, 绝不能掉以轻心, 努力克服资本主义的负面影响; 辨析和吸纳资本主义文明 的积极东西为社会主义服务并成为社会主义要素, 才能最 终战胜资本主义, 是发展中国特色社会主义和马克思主义 中国化成功之路。

2.2 思想政治理论课程建设承担着马克思主义大众化的使 命

思想政治理论课程建设离不开马克思主义大众化, 即 党的理论不能脱离人民群众。

\subsection{1.马克思主义大众化的涵义}

马克思主义大众化的过程就是马克思主义由抽象到具 体、由深奥到通俗、由被少数人理解掌握到被广大群众理 解掌握的过程。马克思主义大众化, 首先运用马克思主义 的思想和方法来研究和解决大众所关心的问题的研究取 向, 所研究的成果必须大众化; 其次用大众化的语言来把 深刻的道理表达出来的通俗化表述形式。马克思主义大众 化就是毛泽东思想和中国特色社会主义理论的大众化, 不 断地赋予毛泽东思想和中国特色社会主义理论的实践特
色、民族特色和时代特色。当代中国马克思主义的大众化 就是中国特色社会主义理论的大众化。它包含三个方面的 内容: 一实践特色就是要面对和解决实际问题, 贴近人民 群众思想实际; 二是民族特色就是符合中国传统文化, 为 中国人民喜闻乐见，符合中国人习惯和接受方式; 三是时 代特色就是必须和中国现代化历史进程相一致, 反映科学 文化进步的新的实际。马克思主义大众化就是要坚持马克 思主义的指导地位并得以巩固。从现实和未来的视角, 马 克思主义大众化就是要实施马克思主义理论研究和建设工 程, 充分反映中国特色社会主义理论体系最新成果学科体 系和教材体系, 推动中国特色社会主义理论体系进教材、 进课堂、进头脑, 增强理论教育引导群众作用。当代中国 马克思主义大众化的主要任务就是开展中国特色社会主义 理论体系宣传普及活动。

\subsection{2 马克思主义大众化的客观必然性}

马克思主义大众化是中国特色社会主义实践的内在要 求, 是实现中华民族复兴的中国梦的必然要求。

2.2.2.1 中国特色社会主义实践是马克思主义大众化的内在 要求

马克思主义大众化就是从实践中来到实践中去和从群 众中来到群众中去的过程。因此马克思主义大众化是中国 特色社会主义实践的本质要求。马克思主义大众化与当代 中国马克思主义鲜明实践特色是相互促进和统一的。党的 理论创新的实践本质是人民社会实践的体现, 是通过实践 认识、运用、检验和发展理论辩证过程, 是发挥理论“改变 世界”的功能和实现理论的实践价值, 用中国特色社会主义 理论体系武装人民, 是发展马克思主义的重要途径, 并赋 予当代中国马克思主义鲜明的实践特色。

2.2.2.2 中国特色社会主义理论体系的发展和增强实践性是 马克思主义大众化的群众基础, 是马克思主义大众 化的必然途径, 是党理论创新宝贵经验。

马克思主义理论只有为人民大众所接受和掌握的大众 化理论, 才有旺盛生命力。理论与实践、理论与群众相结 合的过程是马克思主义大众化过程。中国特色社会主义实 践推进马克思主义大众化, 科学理论转化为物质力量是实 现理论为实践服务的历史使命, 并在马克思主义大众化过 程中, 不断得到提升人民的理论思维能力和理论水平, 是 奠定党的理论创新的群众基础。

2.3 思想政治理论课程建设承担着马克思主义时代化的使 命

思想政治理论课程建设离不开马克思主义时代化, 即 党的理论不能脱离时代发展。 


\subsection{1 马克思主义时代化的涵义及其特征}

马克思主义时代化是马克思主义与时代发展同进步, 并在时代发展中把握时代特征、掌握发展规律、揭示发展 趋势、引领时代发展方向。

\subsection{2 马克思主义时代化特征}

马克思主义时代化具有开放性、概括性和预见性的特 征, 具体如下:

\subsubsection{1 开放性是马克思主义时代化基本前提。}

马克思主义要勇于面对发展中出现新情况新问题; 吸 收新思想新理论合理内容; 参与国际国内思想理论领域竞 争, 具备与时俱进的理论品格。开放性就是要在开放中吸 纳、竞争和发展, 这是当代中国马克思主义的理论胸怀和 理论勇气的体现。

\subsubsection{2 概括性是马克思主义时代化核心}

马克思主义时代化是深刻研究当代世界政治、经济、 文化、社会、生态、科技、军事等诸多复杂时代现象背后 本质变化, 揭示新思想新理论的时代本质和发展规律, 批 判吸收各种新思想新理论的合理内容, 作出新的理论概括, 提出新的理论观点, 丰富自身理论体系, 增强理论的说服 力和感召力。马克思主义时代化要求运用中国特色社会主 义理论体系分析实际问题, 在分析实际问题中概括形成新 的理论观点。

\subsubsection{3 预见性是马克思主义时代化重要特征}

把握当代发展规律和现实情况基础上的理论预见性是 对未来发展趋势和方向的科学预测。马克思主义时代化是 领着时代走, 具有预见性特征。马克思主义时代化要跟上 时代发展步伐, 走在时代发展前列, 引领时代发展方向。

\section{3.马克思主义时代化的客观必然性}

\subsection{1 占领思想理论制高点的客观要求}

人类社会和自然界、国际国内出现的新变化、新特征 和新规律, 都深化人类对自然、社会和自身规律的认识。 经济全球化, 科技信息化, 思想文化发展多元化, 政治、 经济、科技、法律、教育等领域中各种思想理论的竞争日 趋激烈。马克思主义只有与时代发展同进步, 不断创新和 发展, 才能在竞争中立于不败之地。

\subsection{2 党的先进性的客观要求}

思想理论的先进性是党的先进性与决定其他方面的先 进性的基础。马克思主义时代化必须以马克思主义为指导, 准确把握时代主题, 准确把握我国国情和社会主要矛盾以 及我国世界上最大发展中国家的实际, 及时总结党领导人 民创造的新鲜经验, 不断推进党的理论创新和发展。

\section{3. 解决时代问题是马克思主义中国化、大众化、时代 化的途径}

中国特色社会主义理论就是马克思主义中国化大众化 时代化, 是思想政治教育的组成部分, 关键就在于解决方 法问题以及思想教育成败, 也是实现马克思主义中国化大 众化时代化的关键。针对各种社会思潮与马克思主义争夺 思想空间; 现有理论与现实存在的矛盾; 对马克思主义淡 化甚至抵触的态度; 传统传播手段和方法难以应对马克思 主义中国化大众化时代化的挑战, 首要任务是用中国特色 社会主义理论体系武装全党, 使党员干部学马列、懂马列、 信马列、行马列, 实现党员干部的马克思主义中国化大众 化时代化, 基途径主要是学习、宣传和研究。

\section{1 中国特色社会主义理论体系的学习}

马克思主义中国化大众化时代化的主体是党员干部, 特别是在高校青年学生、党员和干部进行有组织的马克思 主义理论学习培训工作。中国特色社会主义理论体系一旦 被党员干部理解掌握, 经过宣传教育变成群众的理论; 坚 持不解地用马克思主义理论特别是中国特色社会主义理论 体系的灌输党, 并在指导实践发挥作用, 提高党员干部的 理论和觉悟水平, 解决地方政府落实政策变形、地方决策 脱离党群关系所引发群体事件、党政官员急功近利, 搞政 绩工程变成伤民工程、地方政府脱离实际, 做出违背科学 发展原则的行为等问题; 坚定马克思主义理想信仰, 克服 利已主义、对群众苛求严厉、对已宽容开放, 特别是严重 腐败问题, 腐败就是对马克思主义和社会主义信仰的缺失。 所以, 推进当代中国马克思主义中国化大众化时代化“灌 输” 是基本教育手段, 也是马克思主义理论教育的基本途 径。列宁认为开展共产主义教育必须“灌输”。邓小平认为 学习马克思主义, 要进行必要的“灌输”。我们需要的是生 动、说理、艺术化的并取得较好效果的灌输; 而不是机械 的、枯燥、效果不好的灌输。党的十六大以来在推进马克 思主义中国化最新成果大众化方面进陆续推出的如《理论 热点面对面》、 《六个“为什么”》等优秀通俗理论读物及 电视理论作品。其突出特点是教给给人民群众“怎么看”和 “怎么办”。“怎么办”是运用马克思主义立场、观点、方法 解决实际问题, 是用党的理论创新成果指导实践的内在要 求。

\section{2 中国特色社会主义理论体系的宣传}

马克思主义中国化大众化时代化的实现是由理论和宣 传工作者来“化”的。理论和宣传工作者是中国特色社会主 义理论体系中国化大众化时代化宣传教育的主体。中国特 色社会主义理论体系教育和对学生的“进学校、进教材、进 
课堂、进头脑”的四进活动, 以互联网、手机媒体为代表的 新媒体, 送理论下基层、下乡活动, 理论和宣传工作者确 实做了方式方法的创新。信息传播单向的效果不满意的原 因是与基层群众的联系少和了解有限; 缺乏群众性语言与 群众沟通相对困难; 被视为是官方意志代言人而被群众主 动疏远。也是理论宣传工作者不能解释地方经济下滑、群 众生活困难、无法解释官员群体性腐败行为、无法论证地 方政府政绩工程的合理性, 所以宣传必须以追求吸引力为 基础的广泛性, 宣传关键是增强理论宣传的吸引力, 用群 众语言向群众进行中国特色社会主义理论体系宣传教育工 作最为有效的途径和形式, 达到说理充分、形象生动、征 服人心的宣传目的。群众创造的讲道理与讲故事、大主题 与小切口、普通话和地方话等传播方法, 是推动马克思主 义中国化大众化时代化的宝贵经验。中国特色社会主义理 论体系为人民群众理解掌握和运用, 靠的是全心全意为人 民服务精神感染群众提高群众的马克思主义信仰。

\section{3 中国特色社会主义理论体系的理论研究}

理论研究目标就是使中国特色社会主义理论体系为大 众普遍理解掌握并自觉践行并成为大众所认同的信仰, 积 极参与到实现中华中华民族近代最伟大的中国梦的实践中 去。理论通俗化就是理论成果贴近实际、贴近生活、贴近 群众, 并转化为人民群众喜闻乐见的民族的生动形式, 从 大众生活的角度来阐释理论创新的内涵, 用大众熟悉的语 言和具体生动的事例来回答大家关心的理论问题和实际问 题。这是基于实践需求的有的放矢的创造性理论教育活动。 坚持理论通俗化宣传能激发群众的理论兴趣以及增强马克 思主义大众化教育的实效。马克思主义中国化、大众化、 时代化需要迫切解决问题是改进文风和话风, 着手解决群 众对当代中国马克思主义的认同信仰问题。

\subsection{1 中国特色社会主义理论体系理论宣传与解决现实问题 的结合 \\ 包括高校大学生在内的广大群众对马克思列宁主义、} 对中国特色社会主义理论的信仰, 关键是党的政策能否从 群众利益出发以及有效解决社会的各种矛盾, 特别是为群 众解决实际困难。革命战争年代的群众从中国共产党为民 做实事中认识党、相信党, 信仰马克思主义, 积极参与革 命事业。中国共产党在国家治理现代化的过程中只有解决 群众包括医疗、教育、住房以及养老等实际问题, 才能得 到群众的拥护。因此理论宣传的实践标准是否按群众实际 利益思考问题, 按群众利益要求解决问题, 为群众办好事、 办实事。只有这样, 才能被人民群众理解、接受和信仰马 克思主义中国化、大众化、时代化。

\subsection{2 理论工作者理论水平和道德示范相结合}

实现马克思主义中国化、大众化、时代化, 理论工作 者必须由坚定的马克思主义信仰和道德示范的力量。理论 工作者不能痴迷邪教和有神论; 不能只讲个人利益、不讲 奉献社会; 理论教育宣传投入与理论工作者品行不佳的矛 盾引起群众的反感和负面作用。理论工作者必须有高超的 学术上水平而且还要有高尚思想品德, 自觉树立和践行社 会主义核心价值观, 带头倡导良好社会风气, 在实现以理 服人的同时更要以德感人。

\subsection{3 实现干部“说教”与“身教”相结合}

实现马克思主义中国化、大众化、时代化要求党员领 导干部要有所作为。中国特色社会主义的巨大成并没有提 升民众的马克思主义信仰，关键是利益集团的利益固化而 无视群众利益。马克思主义的影响力、感召力是靠先进分 子“身教”出来的。战争年代马克思主义理论之所以能够打 动群众、凝聚民心, 关键是党员干部身先士卒、不搞特殊 化, 无私奉献的巨大感召力。今天在宣传马克思主义下大 工夫, 做了方式方法的创新而收效微小的原因是领导干部 的腐败行为所抵消, 对马克思主义造成致命的冲击。因此 党员干部要以讲马列, 行马列, 信马列, 牢固确立的人生 信念, 练就过硬本领, 全心全意为人民服务, 推动群众学 习实践马克思主义的自觉性。

\subsection{4 先进典型的引导}

邓小平指出: “学马列要精, 要管用的。”[4]马列主义 实践品格就是在实践中学习理论、推进马克思主义中国化、 大众化、时代化。先进典型包括先进人物、先进集体、先 进单位、先进地区等, 鲜明地体现马克思主义的真理性和 “管用”的实践性，具有巨大的示范引导作用。以焦裕禄、 宋雨水、王彦生们的先进典型示范引路, 对于推动马克思 主义中国化、大众化、时代化无疑具有重要的方法论意义。 马克思主义中国化、大众化和时代化是有机整体, 相辅相 成、相互促进, 其中中国化是时代化的基础, 时代化是大 众化的核心, 大众化是中国化和时代化的必然归宿。马克 思主义中国化、大众化和时代化是阶段性和连续性统一, 是马克思主义理论创新和我党理论创新的永恒主题。

\section{参考文献 (Reference)}

[1] CPC Central Committee selected documents: eleventh copies of. Central Party School Press 1991. PP. 658-659.

[2] Editorial Committee of Central Committee of Communist Party of China. Deng Xiaoping literature anthology: volume third. Beijing: People's publishing house. 1993:150[1], 65-66[2].

[3] Li Zhichang. The essence on Marx's three party. 2010-07-25. Journal of Party School of Yunnan Province. 